\title{
A MORTE PEla ESPADA: O SUICÍdio RITUALÍSTICO JAPONÊS ANALISADO À LUZ DA TEORIa de Émile DuRKheim
}

\author{
Alana Camoça Gonçalves de OLIVEIRA*
}

RESUMO: O Seppuku era uma forma de suicídio tradicional do Japão feudal e, ao longo da história, foi utilizado pela classe guerreira japonesa (samurai) como uma forma de morrer de maneira honrosa e servindo ao seu mestre. Considerando que o suicídio japonês pode ser interpretado como uma imposição do meio social e das regras que permeavam a sociedade japonesa da época, o presente artigo tem como intuito analisar o suicídio samurai como um fato social e, para fazê-lo, utiliza-se do arcabouço teórico da teoria do suicídio de Émile Durkheim. A partir das concepções sobre as quatro tipologias de Durkheim do suicídio (egoísta, altruísta, fatalista ou anômico), a hipótese central deste artigo é de que o Seppuku pode ser categorizado como uma forma de suicídio altruísta, que está estritamente relacionada com o meio social e com a cultura japonesa.

PALAVRAS-CHAVE: Suicídio. Japão. Samurai. Seppuku. Émile Durkheim.

\section{Introdução}

A sociedade japonesa fornece materiais únicos para os estudos sociais sobre o ato de tirar a própria vida, sendo um dos países com as mais altas taxas de suicídio do mundo. Somente no ano de 2014, por exemplo, o Japão registrou uma taxa de 18,5 suicídios para cada 100 mil habitantes (BBC, 2015). Historicamente, uma das práticas de suicídio mais antigas do Japão é o Seppuku (切腹) ou Harakiri (腹切り), que era uma forma ritualizada do ato que perdurou durante séculos,

\footnotetext{
UFRJ - Universidade Federal do Rio de Janeiro. Instituto de Economia. Rio de Janeiro - RJ - Brasil. 22290-250 - alanacamoca@gmail.com. https://orcid.org/0000-0003-0330-3368.
} 
representando uma insígnia, um ato de coragem e de honra reservado para os militares - precisamente, para os samurais - durante o Japão feudal.

Tal prática foi institucionalizada ao longo da história japonesa, ganhando gradativamente mais ritos e significados. O suicídio simbolizado pelo Seppuku era uma forma de dever; relacionava-se com a honra e com as possíveis falhas humanas cometidas pelos samurais. Considerados como um símbolo de heroísmo e adoração popular em diversos filmes, os samurais foram retratados em variadas séries animadas (animes) e revistas em quadrinhos japonesas (mangás), que os apresentam, inclusive, realizando o ritual do suicídio, o que se correlaciona com a cultura japonesa e com o meio social (RUSSELL; METRAUX; TOHEN, 2016).

Nesse sentido, ao analisarmos o suicídio japonês ritualístico dos samurais, estamos considerando uma forma altamente institucionalizada desenvolvida ao longo da história do arquipélago que expressa uma filosofia sobre a vida e a morte, bem como um ritual que precisa ser analisado por um viés social. De fato, o ritual se tornou parte inerente da história e dos aspectos culturais nipônicos e, como afirma Fuse (1980, p. 57, tradução nossa), "O ato de Seppuku tem sido cultivado na tradição cultural do Japão como um comportamento socialmente e culturalmente prescrito."”

Diante de tal compreensão, como debateremos no presente artigo, o Seppuku pode ser caracterizado como um costume, uma regra social, um fato social. Apresentando a história dos samurais, seus preceitos e as questões relacionadas aos samurais e à cultura japonesa, visamos debater o Seppuku à luz da teoria de suicídio de Émile Durkheim (2008) abordada no livro O Suicídio.

De fato, utilizamos uma teoria ocidental para explicar um rito oriental, com tradições que são permeadas por valores diferenciados. Apesar disso, compreendemos que as tipologias de Durkheim nos fornecem mecanismos para compreender o ato social e, do nosso ponto de vista, nos possibilita debater sobre a existência de uma forma de suicídio que era vista como positiva pela sociedade. Ao lançarmos a hipótese sobre o suicídio japonês como um exemplo de suicídio altruísta, visamos elucidar o caso no qual a integração ao meio social colabora para o ato de tirar a própria vida, promovendo, com isso, o cumprimento de uma função social.

Para analisarmos o suicídio samurai à luz da teoria de Durkheim (2008), apresentaremos inicialmente um debate sobre as tipologias do suicídio de Durkheim e sua teoria social e acerca de como definimos o suicídio altruísta. Na segunda parte do artigo, abordaremos como a prática do suicídio é interpretada de forma diferente, dependendo do meio social de sua época. Dessa forma, apresentaremos como, no Japão feudal, o suicídio era um ato positivo e como tal prática se tornou um dos emblemas da cultura samurai.

\footnotetext{
1 No original: "Seppuku has been nurtured in Japan's cultural tradition as a socially and culturally prescribed role-behaviour".
} 


\section{O suicídio como fato social}

No livro As Regras do Método Sociológico, Émile Durkheim (2002) enfatizou a necessidade de transformar a sociologia em uma ciência empírica, pressupondo a necessidade do uso da empiria para a comprovação de princípios teóricos. Em tal obra, o autor denomina o "fato social" como "toda maneira de fazer, fixada ou não, suscetível de exercer sobre o indivíduo uma coerção exterior; ou ainda, toda maneira de fazer que é geral na extensão de uma sociedade dada e, ao mesmo tempo, possui uma existência própria, independentemente de suas manifestações individuais" (DURKHEIM, 2002, p. 13).

De forma simplificada, os fatos sociais são externos ao homem, são anteriores a ele e permeiam a sociedade. Nesse sentido, são impositivos sobre a ação humana por meio de relações estabelecidas entre o indivíduo e a sociedade. Tais fatos condicionam o comportamento dos homens, que instruem a sua forma de agir, o seu costume e os seus deveres por intermédio de imposições sociais. Regras morais, jurídicas, dogmas religiosos, sistemas financeiros, obrigações familiares e responsabilidades enquanto cidadão são exemplos de fatos sociais.

De acordo com Durkheim (2002), os fatos sociais definem o que é normal e o que é anômico em uma sociedade, tendo em vista que existem padrões morais superiores aos indivíduos que definem os comportamentos aceitáveis presentes no interior da sociedade. Existem forças institucionalizadas ou não institucionalizadas que fazem do homem um ser social e não individual e, por meio dessas forças que rondam a sociedade e que permeiam a mente de cada indivíduo que a ela pertence, regras, normas, costumes e hábitos são construídos e difundidos. Dessa maneira, os homens vivenciam um processo de socialização desde seu nascimento e deixam de ser seres ainda não socializados, para se tornarem indivíduos sociais em uma sociedade.

Nem toda ação humana é um fato social, visto que ela deve atender a três características básicas: ser geral, exterior ao indivíduo e coerciva. Ou seja, para que uma ação humana seja considerada como um fato social, é preciso que ela responda a normas sociais externas anteriores à vontade e à consciência individual de cada indivíduo; ademais, elas precisam ser coercivas, tendo em vista um ambiente social que constrange e influencia o comportamento dos homens.

No livro O Suicídio, Durkheim (2008) busca entender os motivos que levam os homens a atentarem contra a própria vida, tendo em vista que os obituários, por exemplo, são insuficientes e não tratam de uma verdade sobre o fato, visto que apresentam uma opinião de outrem sobre o acontecido. Giddens (1981) argumenta que o objetivo de Durkheim na obra é analisar a natureza do suicídio, partindo não das motivações pessoais, mas das sociais. Steiner (2016) aponta que Durkheim está preocupado em analisar aspectos da socialização do indivíduo no meio social, pontuando tanto aspectos sobre a integração como acerca da regulação social. 
Mas seria o suicídio um fato social? Afinal, o suicídio é muitas vezes um sintoma, uma consequência de outros fatos sociais sobre os quais um sujeito é interpelado diariamente na sua convivência e ao longo da sua vida. Durkheim (2008, p. 167) define o suicídio como "todo o caso de morte que resulta direta ou indiretamente de um ato positivo ou negativo praticado pela própria vítima, ato que a vítima sabia dever produzir este resultado. A tentativa de suicídio é o ato assim definido, mas interrompido antes que a morte não tenha resultado". Como aponta Giddens (1981, p. 87), "uma taxa de suicídio é mais que um índice de incidência de atos de autodestruição. É um fato social em si mesmo; consequência de um conjunto complexo de eventos que envolvem numerosos atores sociais: parentes, amigos, médicos, polícia, magistrados, encarregados de investigar casos de morte suspeita, etc.".

Contudo, mesmo que o suicídio seja um ato que apenas afeta fisicamente o próprio indivíduo que o cometeu, isso não quer dizer que seja uma ação regida somente por valores pessoais (MUELLER, 2017). Além disso, indo de encontro às percepções da psicologia, Durkheim lança a concepção de que, considerando-se o conjunto dos suicídios cometidos numa sociedade, constata-se não a simples soma das unidades independentes, e sim a coleção de um todo. Por esse motivo, a natureza do suicídio é eminentemente social (DURKHEIM, 2008).

Do nosso ponto de vista, o suicídio pode ser considerado um fato social, na medida em que ele se constitui por uma tendência presente em todas sociedades, algo que Durkheim (2008) denomina como aptidão definida para o suicídio. Afinal, cada sociedade tem uma predisposição para a existência de um determinado número de mortes por suicídio que acontecem não com indivíduos isolados, mas com indivíduos enquanto membros da sociedade.

De acordo com o sociólogo, o suicídio pode ser categorizado a partir de quatro tipos: (i) o egoísta, (ii) o fatalista, (iii) o altruísta e (iv) o anômico. O primeiro tipo de suicídio é aquele que tem como característica predominante (i) o egoísmo. Nesse caso, o ato de se suicidar varia inversamente à integração das pessoas na sociedade religiosa, política e/ou doméstica. As relações entre os indivíduos e a sociedade se perdem e, por isso, há uma individualização excessiva perante o meio social ${ }^{2}$. Em contraposição, o (ii) suicídio fatalista demonstra que o indivíduo estaria tão preso à sociedade e aos valores normativos que se sentiria pressionado pela ordem social a cometer o ato. Diante da opressão social, a única opção viável ao indivíduo seria o suicídio (STEINER, 2016).

O terceiro tipo de suicídio é (iii) o altruísta. Essa categoria delimita os indivíduos que estão integrados no coletivo social de tal forma que às vezes existe

\footnotetext{
2 O afastamento do homem do meio social torna-o separado da sociedade; assim, perde-se o vínculo entre o indivíduo e o grupo, e o valor da vida deixa de deter o mesmo significado.
} 


\section{A morte pela espada: o suicídio ritualístico japonês analisado à luz da teoria de Émile Durkheim}

o dever de se matar, sendo este muitas vezes considerado um ato de heroísmo. Nesse contexto, a ação de tirar a própria vida pode ser pensada como uma forma positiva do suicídio. Assim, precisamos explorar tal tipo com maior profundidade e ampliar o debate para além das obras de Durkheim, como faremos na próxima seção.

O quarto e último tipo, mas não menos importante, é o suicídio (iv) anômico. Nesse caso, o indivíduo não encontra razão de existência na sociedade e nem em si. Surge em um momento de caos, em que a normalidade social não pode ser mantida. De acordo com o autor, o maior número de suicidas é encontrado nessa categorização, e os suicídios que ocorreram em 1929, quando houve, em resumo, a crise econômica que ocasionou a falência de diversas empresas e organizações, são um exemplo disso (DURKHEIM, 2008). Observa-se nos casos supracitados que o suicídio pode ocorrer tanto quando o homem é alienado à sociedade quanto quando ele é integrado demais a ela (TSAI; CHANDLER, 1993). Em suma, é possível sintetizar as categorizações de suicídio na concepção de que "muito pouca integração acarreta em egoísmo e muita integração acarreta no suicídio altruístico. Muito pouca regulamentação produz anomia e muita regulamentação produz suicídios fatalistas"3 (TSAI; CHANDLER, 1993, p. 245).

\section{O suicídio como um ato positivo e socialmente aceito}

O suicídio altruísta pode ser categorizado de três formas: obrigatório, opcional ou agudo. O primeiro caso simboliza o suicídio como um dever, de modo que se espera que o indivíduo, devido às normas culturais, cometa o suicídio. Exemplos desse tipo seriam: (a) os servos que se matam após a morte de seus reis ou senhores, como ocorria no caso do Egito, (b) idosos e doentes que desejavam fazê-lo por não cumprir (ou poder cumprir) mais qualquer função social na sociedade, ou, ainda, (c) as viúvas que cometiam suicídio após a morte de seus maridos (DURKHEIM, 2008; STACK, 2004). O segundo caso é semelhante ao primeiro no que diz respeito à velhice e à doença, mas podia ser encarado como opcional em algumas sociedades primitivas (STACK, 2004). Por fim, a terceira subcategorização refere-se ao suicídio realizado por fins religiosos, usualmente para alcançar a superioridade espiritual (STACK, 2004).

Durkheim (2008) argumenta que a modernização levou ao aumento das taxas de suicídio no mundo, onde, com a industrialização, os avanços tecnológicos e as transformações no meio social, concluiu-se que o suicídio egoísta e anômico são as formas mais comuns na sociedade atual, enquanto o altruísta e o fatalista são as formas menos observáveis no contexto moderno, estando presente somente em

\footnotetext{
3 No original: "too little integration leads to egoistic and too much integration to altruistic suicide. Too little regulation produces anomic and too much regulation fatalistic suicide"
} 
sociedades tradicionais ou primitivas. Para o presente artigo, não é nosso objetivo revisitar outras sociedades, testar e debater se de fato o suicídio altruísta e o fatalista são raros na modernidade. Contudo, no que tange ao debate sobre o Japão, alguns atores visaram testar tais hipóteses ao analisar o caso do arquipélago, chegando a conclusões contrárias às afirmativas de Durkheim (2008). Mamoru Iga (1986; 1981), por exemplo, analisando a sociedade japonesa no século XX, conclui que, no Japão, ocorria o inverso:

O pessimismo budista e rígidas regulamentações sociais, seja formal ou informalmente, impostos aos socialmente inferiores, incluindo jovens e mulheres, contribuem para o suicídio "fatalista". O conceito animista do espírito do falecido permanecendo como membro da família; a ênfase dada à solidariedade familiar; e a ênfase dado pelo Confucionismo à lealdade, auto-sacrifício, e honra - todos contribuem para o suicídio altruístico (...) É possível dizer que o suicídio no Japão é mais ou menos um mecanismo de ajuste institucionalizado. ${ }^{4}$ (IGA, 1981, p. 29 , tradução nossa).

Posteriormente, Tsai e Chandler (1993) utilizaram-se de métodos quantitativos para testar a hipótese de que o comportamento da sociedade japonesa na atualidade era diferente em relação ao esperado por Durkheim (2008). Os autores chegaram à conclusão de que os suicídios no Japão, em sua maioria, ainda detém traços que os categorizam como altruístas e/ou fatalistas ${ }^{5}$, traços estes que têm relação com a própria cultura e estrutura social do país.

Se o suicídio altruísta e/ou fatalista é algo presente na sociedade japonesa do século XX, quais seriam os pilares culturais que baseiam tal predisposição social? Para respondermos a tal indagação, recorremos a uma análise da figura do samurai e do suicídio ritualístico japonês. Nesse sentido, precisamos primeiro considerar que o suicídio pode deter um caráter positivo dentro da sociedade e, em segundo lugar, que a valorização da morte era um valor social que influenciava a sociedade feudal nipônica (IGA, 1981).

Referente a tal fato, mesmo na modernidade, um exemplo utilizado por Durkheim e que pode ser pensado no século XX são as ações dos militares e de civis que optaram pela morte em prol da Nação. Nesse caso, o Japão nos fornece um exemplo moderno que simboliza tal forma de suicídio, visto que, na década de

\footnotetext{
4 No original: "Buddhist pessimism and the strict social regulations, whether formal or informal, imposed upon social inferiors, including youth and women, contribute to "fatalistic" suicide. The animistic conception of the deceased person's spirit remaining as a member of his family; the emphasis on family solidarity; and the Confucian emphasis on loyalty, self-sacrifice, and honor - all contribute to altruistic suicide (...) It may be said that suicide is a more or less institutionalized adjustment mechanism in Japan" 5 Nos estudos dos autores, a metodologia utilizada não permite compreender a dissociação dos dois tipos de suicídio.
} 


\section{A morte pela espada: o suicídio ritualistico japonês analisado à luz da teoria de Émile Durkheim}

1930, durante o expansionismo japonês e a Segunda Guerra Mundial (1939-1945), diversos militares e até mesmo cidadãos civis japoneses se suicidaram como um pedido de desculpas ao Imperador após a derrota.

Ainda está fresco em nossas memórias o fato de que, recentemente, durante a segunda guerra mundial, diversos oficiais das forças armadas japonesas cometeram o Seppuku em ilhas do Pacífico diante de soldados norte-americanos que ficaram perplexos com a visão. Imediatamente após o final da guerra, em 1945, o chão sereno do exterior do Palácio Imperial em Tóquio foi tingido de vermelho com o sangue de homens e mulheres japoneses, tanto militares quanto civis, que calmamente cometeram Seppuku aos milhares, como forma de "desculpas" ao Imperador por terem perdido a guerra" (FUSE, 1980, p.57, tradução nossa).

Contudo, uma outra maneira de compreender o suicídio de forma positiva e para além de um ato heróico em prol da pátria consiste em analisar os princípios da própria tradição japonesa e os axiomas de responsabilidade das elites samurais. Tais fatores são associados ao suicídio por obrigação, devido à integração do indivíduo com o meio social e cultural.

\section{O suicídio samurai e os seus motivos}

Apesar de um tabu na atualidade, o suicídio, antigamente, era encarado de forma diferente do que o é dos dias atuais. Na Antiguidade, diversos povos ocidentais partilhavam um caráter comum em relação ao suicídio de idosos. Esperava-se que, a partir de uma certa idade e/ou devido às debilidades da velhice, os homens se suicidassem. Na Roma e na Grécia, por exemplo, o suicídio era apoiado sob condições específicas e, para fazê-lo, era necessário solicitar à comunidade política (HETCH, 2013). Os próprios escritos bíblicos não condenavam as passagens de suicídio e, inclusive, o ato era uma prática adotada por cristãos, o que colocava em risco a própria existência da igreja $(\mathrm{HETCH}, 2013)$. De fato, a grande mudança com relação ao suicídio emergiu com Santo Agostinho, que trouxe argumentos sobre a proibição do ato de se matar, e pela categorização de tal ação como pecado (GOES, 2004).

\footnotetext{
6 No original: "It is still fresh in our memory that as recently as World War II countless numbers of Japanese military officers committed Seppuku in Pacific islands before the eyes of stunned American fighting men. Immediately after the end of the war in 1945, moreover, the serene outer ground of the Imperial Palace in Tokyo was dyed with blood by some Japanese men and women, both military and civilian, who calmly committed Seppuku in tens and hundreds as an "apology" to the Emperor for having lost the war".
} 
Como aponta Young (2002), inicialmente, o suicídio no ocidente era visto diversas vezes como um problema religioso, moral, legal e médico, enquanto, no século XXI, o ato de cometer o suicídio começou a ser tratado como a evidência de uma doença mental. Contudo, no Japão, o suicídio "não é visto como a negação do valor da vida, mas como uma afirmação do valor dado à devoção moral ao próximo"7 (YOUNG, 2002, p. 413). O suicídio é derivado de um senso de dever (giri) e, por esse motivo, está relacionado à integração do indivíduo ao meio social. Tais ações podem ser vistas nos samurais, nos kamikazes $^{8}$ e, inclusive, mesmo que de forma mais rara, na atualidade?

Segundo Young (2002), o indivíduo japonês está embebido por valores sociais e, como consequência, o grupo é de central importância para ele, de tal modo que o ato de autos sacrifício é altamente valorizado (FUSE, 1980).

No ocidente, o indivíduo é entendido como autônomo, independente, e livre, e, além disso, possuidor de direitos inalienáveis. O que vemos no Japão, em contraste, é o conceito do indivíduo como inserido na sociedade e dependente dos outros, e complacente dos desejos dos outros. (...) Cada indivíduo recebe os benefícios (on) do grupo e possui deveres não escritos (giri) pelos quais é responsável porque, através deles temos como resultado a harmonia $(\mathrm{wa})$ social $^{10}$ (YOUNG, 2002, p. 415, tradução nossa).

Em linhas gerais, os samurais surgiram como classe guerreira na época feudal do Japão entre os séculos VIII e XIX. Ser um samurai era um prestígio social, uma vez que a classe guerreira ocupava os mais altos cargos no Japão feudal.

\footnotetext{
7 No original "is not seen as the denial of the value of life, but as an affirmation of the value of one's moral duty to others"

8 Eram soldados japoneses que se suicidavam como ato de amor à Nação, vinculados às questões de pertencimento à sociedade japonesa e de agir em prol desta. Os kamikazes arremessavam os aviões contra navios inimigos em momentos que não tinham mais combustível para alimentar o motor, ou, muitas vezes, por já terem sido treinados especificamente para uma missão suicida. Argumenta-se que os kamikazes já sabiam que iriam morrer pela pátria e pelo imperador, e muitos sentiam orgulho de serem escolhidos para realizarem tais atos.

9 Em 2004, houve um escândalo envolvendo uma empresa de aves domésticas que falhou ao enviar relatórios sobre a morte de vários pássaros em suas fazendas para a prefeitura de Kyoto. Posteriormente, foi descoberto que os pássaros morreram de uma doença aviária, e diversas mortes ocorreram em humanos na Ásia no período. Existiam relatos sobre a possibilidade de um corvo ter sido infectado pelos vírus dos pássaros na fazenda e disseminado para outros animais. O casal se enforcou próximo à fazenda durante a investigação, o que foi considerado como um ato de arcar com as responsabilidades da falha de enviar relatórios sobre a morte dos pássaros, sendo também um pedido de desculpas para aqueles que morreram vítimas do problema (RUSSELL; METRAUX; TOHEN, 2016).

${ }^{10}$ No original: "In the west, the individual is conceived of as autonomous, independent, and free, and, moreover, as possessing inalienable rights. What we find in Japan, in contrast, is a conception of the individual as socially embedded as dependent on others, and as compliant to others wishes. (...) Each individual receives benefits (on) from the group and has unwritten duties (giri) for which he or she is responsible because through their fulfillment social harmony (wa) results."
} 


\section{A morte pela espada: o suicídio ritualístico japonês analisado à luz da teoria de Émile Durkheim}

Inicialmente, a função dos samurais era coletar impostos e servir ao Império por meio de trabalhos administrativos (BENESCH, 2014), sendo que, somente entre o século X e XII, a figura do samurai tomou forma e ganhou funções militares e de guerra como são conhecidos e difundidos atualmente, principalmente na cultura pop $^{11}$ (RUSSELL; METRAUX; TOHEN, 2016).r Do ponto de vista etimológico, a palavra samurai (侍) significa literalmente no japonês "aquele que serve", referindose diretamente à função de servir ao imperador e ao soberano no Japão feudal.

Como código de conduta, os samurais seguiam o caminho do Bushido (BENESCH, 2014). Segundo Inazo Nitobe (2005), o Bushido é o código de princípios morais ao qual os guerreiros eram obrigados ou instruídos a seguir e a difundir. Não é um código escrito, e consiste em poucas máximas transmitidas por meio dos atos de fala durante gerações, influenciando a cultura militar japonesa ao longo dos anos e tornando-se um dos pilares das ações do indivíduo nipônico ao longo dos séculos. Seguir o caminho do guerreiro era viver a vida com lealdade, fidelidade, autossacrifício, justiça, modos refinados, humildade, espírito marcial e honra. E, acima de tudo, quem trilhava o caminho do guerreiro deveria morrer com dignidade para não danificar a reputação de seu nome e do nome da família, do feudo e do seu senhor.

O samurai deveria servir com lealdade incondicionalmente e, por isso, um de seus axiomas era o de que eles deveriam dar a vida pelo senhor se fosse preciso (NITOBE, 2005). Apesar do código do Bushido nunca ter sido escrito, em 1716, Yamamoto Tsunetomo, um vassalo do feudo Nabeshima, tentou recuperar os valores samurais em tempos de paz, escrevendo o livro chamado Hagakure ou "Folhas ocultas" ou ainda "Oculto pelas folhas" (TSUNETOMO, 2004). Os escritos do Hagakure recuperaram a ideia da filosofia samurai e ressaltavam ensinamentos que nunca haviam sido propriamente escritos. Como não eram escritos, durante séculos os valores dos samurais eram como energias, transmitidos pela sociedade e pelos ensinamentos das artes marciais e familiares como correntes que penetraram a sociedade japonesa como um todo.

O Hagakure traz aprendizados práticos de ideias e de concepções e valores que deveriam ser seguidos pelos samurais para se manterem puros e serem verdadeiros guerreiros. Em tal livro, são apresentados quatro votos de conduta que deveriam ser e que foram seguidos pelos samurais ao longo dos anos. O primeiro e o segundo deles determinam que o guerreiro feudal japonês deveria (i) servir ao mestre e precisava (ii) executar suas funções com primazia, sem cometer falhas ou erros. O terceiro e o quarto votos dos samurais pregavam (iii) a devoção aos

\footnotetext{
${ }_{11}$ Não faltam exemplos de filmes (hollywoodianos e japoneses), animes e mangás que retratam sobre os samurais. Para citar alguns temos O Último Samurai (2003), Rurouni Kenshin (1994), Os Sete Samurais (1954) e inúmeros outros. Deve-se considerar ainda que o uso de espadas samurais pelos mais diversos personagens e nos mais variados filmes de ficção fazem sucesso na atualidade.
} 
pais e (iv) a manifestação da compaixão para com os seus semelhantes. Em linhas gerais, um guerreiro japonês não poderia ser egoísta ou individualista, visto que suas decisões deveriam levar em consideração o mestre, a família e, acima de tudo, o seu feudo e o povo.

\section{O ritual da morte: o Seppuku e o dever}

O suicídio samurai era um ato comum entre os samurais a partir do século XII e, por trás da prática, existia não só uma preparação ritualística, como também uma simbologia que referencia e se correlaciona com os valores que foram expostos posteriormente no Hagakure. Historicamente, postula-se que um dos primeiros Seppuku registrados no Japão foi o de Minamoto Tametomo em 1170, que cometeu tal ato após perder uma batalha contra famoso clã dos Taira.

De acordo com Maeda (2011, p. 99), desde o período Kamakura (11921333), o Seppuku "foi estabelecido como um método de suicídio. O Seppuku é descrito como um método para expurgar a culpa, pedir desculpas por erros, evitar estigmas, reparar relações com amigos, e provar a própria honestidade" ${ }^{12}$. E, no período Edo (1603-1867), o Seppuku se estabeleceu como uma forma de punição por parte do governo, passando a existir de modo voluntário ou involuntário (punitiva ou comandada). É imperativo compreender que existe uma relação íntima entre "valores culturais e comportamentos culturais aceitáveis. Entendido de forma tão vantajosa do ponto de vista de 'cultura e personalidade', então o Seppuku pode não ser uma forma de comportamento 'psicopatológico""13. (FUSE, 1980, p. 64). Segundo Benedict (1954), os japoneses não têm o sentimento cristão de culpa no momento do suicídio, estando mais inclinados a salvar o seu nome ou proteger a nação por intermédio da realização de tal ato. Como afirma Fuse (1980, p. 62), para os samurais e japoneses influenciados pelo Budismo ${ }^{14}$, "o significado da vida era entendido como a habilidade de uma pessoa de achar o momento e local corretos para morrer" 15 .

\footnotetext{
12 No original: "was established as a method of suicide. Seppuku is described as a method to expiate guilt, to apologize for mistakes, to avoid stigma, to atone for friends, and to prove their own honesty"

${ }_{13}$ No original: "cultural values and culturally approved behaviour. Viewed from such a vantage point of 'culture and personality', then, Seppuku may not be a case of 'psychopathological' behavior"

${ }^{14}$ Segundo Fuse (1980, p. 62, tradução nossa), " desde o período Kamakura (1185-1333), o samurai sofre forte influência do Zen Budismo, que pregava a importância de se transcender a vida e a morte. $O$ Zen foi adotado de forma entusiasmada pelo código do guerreiro samurai (Bushido), no qual a morte era considerada de forma positiva como uma forma de mostrar seu valor e lealdade por toda a eternidade". Nota-se que o confucionismo e o xintoísmo também eram bases do Bushido no Japão, o que pode ser vislumbrado nas concepções de hierarquia familiar e de classe no Japão feudal, por exemplo.

${ }^{15}$ No original: "the meaning of life was understood in terms of one's ability to find the right time and place to die".
} 


\section{A morte pela espada: o suicídio ritualistico japonês analisado à luz da teoria de Émile Durkheim}

Historicamente, o Japão seria o tipo de sociedade na qual o prestígio social está associado ao suicídio e a recusa desta honra tinha efeitos punitivos na pessoa, na família e na Nação (UENO, 2005). Existia um ritual, um modo específico de como conduzir o Seppuku que, em alguns casos, era assistido por outras pessoas. Portanto, o suicídio tinha significado não apenas para a pessoa que morria, mas também para aquelas que ela deixava para trás, incluindo audiências esperadas e não esperadas (MUELLER, 2017; STACK; ABRUTYN, 2015). Nesse sentido, o ritual pode adquirir significados que são compartilhados e adquiridos por meio da interação com outros seres.

No ritual do Seppuku, os passos deveriam ser estabelecidos a partir de uma determinada ordem. A vestimenta, a sequência e o modo como a prática deve ser feita causam a ideia de um ato sereno, homogêneo e previamente ensaiado. Por isso, enquanto um ritual, fortalecia a tradição e a crença, fazendo com que se tornasse algo mais palpável e materializado. Além disso, a ritualização do ato o tornava repetitivo e, por meio da repetição, cada vez mais a crença estava presente no meio social. Existia uma performance e uma expectativa em torno do samurai, que era impelido pelo meio social, pela cultura, pelos costumes e pelas tradições a aceitar e venerar a morte, bem como a apoiar tal ato.

Na maioria dos casos, o ritual seguia a seguinte ordem: o samurai banhava-se para purificar seu corpo e sua alma, vestia uma indumentária tradicional japonesa (normalmente na cor branca) e tomava uma dose de saquê. Então, se ajoelhava ${ }^{16} \mathrm{e}$ enfiava uma wakizashi (espada curta) ou um punhal na barriga, no lado esquerdo, e cortava até o lado direito, deixando assim as vísceras expostas. O Seppuku era considerado uma morte terrivelmente dolorosa, mas o samurai, de acordo com o seu código de honra, não podia demonstrar dor ou medo ao realizá-lo (PINGUET, 1987; FUSE, 1980; BERNESCH, 2014).

O samurai, após abrir o ventre, poderia permanecer vivo por horas ou mesmo dias. Por isso, era cometido o kaishaku (介错), que era o ato de um companheiro ou assistente ${ }^{17}$ que consistia em abrir a garganta do samurai sem romper nenhuma vértebra, para que o samurai não demonstrasse sua dor. Dessa forma, além dos significados social e cultural, existia um valor físico do processo de cometer o ato em si. A utilização da lâmina por parte do guerreiro japonês traz consigo o simbolismo da "alma do samurai" (e do Japão) e, ao mesmo tempo, nas artes marciais japonesas, o hara (腹), ou a parte que representa o abdômen, é considerado como o centro de equilíbrio do corpo tanto físico como espiritual.

\footnotetext{
${ }^{16}$ Em alguns casos, o Seppuku poderia ser cometido em pé, sendo também conhecido como "Tachibara". ${ }_{17}$ É importante dizer que aquele que comete o kaishaku não recebe nenhuma honra ou louros pelo trabalho, todavia, como era um ato de misericórdia e como era necessária destreza e força, quem executava o ato era um samurai experiente.
} 
O ato de cometer o Seppuku poderia ser voluntário, e, nesse caso, a ação de fazê-lo partia do próprio samurai, que enxergava o suicídio como um dever social; ou, em outras situações, o Seppuku poderia ser um ato comandado pelos senhores feudais. No segundo caso, tal ação era ordenada no momento em que o samurai feria a honra do mestre - seja por conta de um ato de desobediência, alguma falha, ou ainda devido a uma derrota - ou atentasse contra a vida de algum nobre. Além disso, era comum que o samurai cometesse o suicídio caso o seu senhor feudal morresse, visto que tradicionalmente ele não poderia servir a nenhum outro senhor em vida como guerreiro (BENESCH, 2014; FUSE, 1980).

Como afirma Fuse (1980, p. 59-60), o suicídio voluntário era chamado de jijin (自尽) e o punitivo ou comandado era conhecido como tsumebara (詰め腹). Ambas as categorias podem se subdividir em tipos de suicídio que simbolizam determinado ato e elencam certos motivos para que tal ação fosse cometida, como apresentamos no quadro a seguir.

\section{QUADRO 1: TIPOS DE SEPPUKU E MOTIVOS}

\begin{tabular}{|c|c|c|}
\hline & Tipos & Motivos \\
\hline \multirow[t]{6}{*}{ Suicídio Voluntário } & Jiketsu & Derrotado em batalha. \\
\hline & Inseki & Assumir responsabilidade pelos erros. \\
\hline & Sacrifício & Salvar um grupo. \\
\hline & Kanshi & Protestar contra a conduta de um lorde. ${ }^{18}$ \\
\hline & Memboku & Provar a inocência de alguém. \\
\hline & Junshi & Seguir o lorde ou alguém após a morte. ${ }^{19}$ \\
\hline \multirow[t]{3}{*}{$\begin{array}{l}\text { Suicídio Punitivo ou } \\
\text { Comandado }\end{array}$} & Munenbara & $\begin{array}{l}\text { Comandado por não cumprir determinadas metas } \\
\text { e objetivos. }\end{array}$ \\
\hline & Funbara & $\begin{array}{l}\text { Comandado após o indivíduo assumir a responsa- } \\
\text { bilidade legal e moral por alguém. }\end{array}$ \\
\hline & Keishi & Punição por ter cometido algum crime. \\
\hline
\end{tabular}

Fonte: Adaptação da tabela de Fuse, 1980.

A prática do Seppuku perdurou durante séculos, mas passou a não ser oficialmente apoiada e completamente endossada pelo governo com a unificação

\footnotetext{
${ }^{18}$ Era cometido como um ato de lealdade porque o samurai se matava para chamar a atenção e advertir o daimyo (senhor) de que algo poderia estar errado.

${ }^{19}$ Caso o senhor feudal do samurai fosse derrotado na guerra e o samurai não cometesse Seppuku, nenhum outro senhor poderia contratá-lo. Nesse momento, o guerreiro renúncia à classe dos samurais e passa a ser chamado de ronin ou "homem onda". Tal nome refere-se à ideia de que, assim como as ondas do mar, esse servo não tem destino. Usualmente, o ronin se tornava um andarilho, fazendo trabalhos menores e até mesmo servindo em pequenas missões de outros feudos.
} 


\section{A morte pela espada: o suicídio ritualístico japonês analisado à luz da teoria de Émile Durkheim}

(1603) e a pacificação do Japão sob a liderança de Ieyasu Tokugawa, com o estabelecimento do Shogunato Tokugawa (1603-1868). Todavia, as práticas não foram esquecidas e continuaram sendo mantidas mesmo após a condenação. $O$ enaltecimento da morte é uma das marcas do período feudal japonês e, mesmo no século XX, as práticas ainda eram realizadas por oficiais militares e até mesmo por cidadãos, que o fizeram principalmente, como mencionamos anteriormente, após o fim da Segunda Guerra Mundial.

\section{O suicídio samurai à luz da teoria de Durkheim}

O Seppuku "é um bom exemplo de comportamento individual sendo subordinado à necessidade de uma coesão social, porque no seu ato autodestrutivo no qual o propósito e significado do indivíduo é tão fortemente definido em termos maiores do que ele próprio que ele rapidamente sacrifica sua própria vida em nome do seu papel social" ${ }^{20}$ (FUSE, 1980, p. 64). Por ser algo endossado e parte fundamental do papel do samurai na sociedade, o suicídio samurai cumpria um papel social e pode ser considerado como um fato social.

Seja ele voluntário ou comandado, considerando a teoria de Durkheim e suas tipologias de acordo com o que apresentamos, qual seria o tipo-ideal ou a categorização que mais se aproxima da prática samurai? Como apresentamos anteriormente, o samurai comete o Seppuku por motivos específicos, que se relacionam com a servidão ao mestre, ao povo, aos pais e à honra (TSUNETOMO, 2004). Partiremos desse prisma em nossa análise a fim de responder essa pergunta.

Tsunetomo (2004) apresenta algumas histórias de samurai e enaltece alguns casos interessantes de Seppuku. Em um dos casos, ele apresenta Sagara Kyuma, um samurai japonês que estava em completa harmonia com o seu mestre feudal e o servia sem questionamentos. De acordo com Tsunetomo (2004) ao recontar a história, Kyuma negligenciou uma reunião que ocorria na casa de campo de seu mestre, adentrando na residência deste de forma disruptiva, causando grande perturbação. Com isso, "após provocar esse incidente, ele, numa atitude galante de desprendimento, pensou apenas na honra de seu mestre e decidiu cometer o suicídio" (TSUNETOMO, 2004, p. 31). Tal ato de Kyuma causou grandes problemas para o senhor e, por esse motivo, o samurai cometeu o Seppuku como um ato de arrependimento e de altruísmo. Afinal, como não serviu ao seu mestre, não agiu em prol daqueles que deveria proteger e, em razão disso, cometeu suicídio como ato de honra e de perdão.

\footnotetext{
${ }^{20}$ No original: "is a good example of individual behavior being subordinate to the needs of social cohesion, because it is an act of self-destruction in which the individual's purpose or meaning is defined so strongly in terms larger than himself that he readily sacrifices his life in the name of his social role"
} 
Associa-se o suicídio samurai com a honra, visto que, para os samurais, um homem existe apenas por uma geração, enquanto seu sobrenome dura até o fim dos tempos, sendo algo típico da cultura da vergonha (BENEDICT, 1954). Para os guerreiros japoneses, a vida não se tornou inaceitável em si mesma, isto é, o samurai não se abate por interesses e angústias pessoais, e a família não sofre com a morte, pois o ato justamente visa impedir o sofrimento das pessoas. Nesse sentido, tudo o que o samurai fizer "deve ser feito em prol de seus pais e mestres, das pessoas em geral, e para a posteridade. Essa é a grande compaixão. A sabedoria e a coragem que vêm da compaixão são as verdadeiras" (TSUNETOMO, 2004, p. 25).

Durante séculos, o ritual japonês tinha apoio do meio social, que enxergava o suicídio como um símbolo de servidão, podendo ser um ato voluntário. Como mencionamos anteriormente, o Seppuku também poderia ser um ato comandado e nem todos os samurais desejavam fazê-lo. Apesar disso, podemos considerar até mesmo uma anomia os samurais que não se sentiam inclinados a cometer tal ato, visto que ia de encontro com os ideais esperados no meio social do arquipélago nipônico.

Nesse sentido, os samurais que decidissem não cometer o suicídio caso fossem ordenados ou caso fosse esperado que eles cumprissem esse papel poderiam ser punidos. Ou seja, o meio social e as regras dos samurais impunham determinados valores que esperavam ser seguidos pelos indivíduos que pertencessem a tal grupo social. Consequentemente, o samurai que recusasse o destino e decidisse viver porque não via sentido na morte:

[...] pelos próximos cinco, dez ou vinte anos de vida, ele seria recriminado pelas costas e estaria marcado pela vergonha. Após a morte, seu cadáver seria coberto de desgraça, seus descendentes inocentes receberiam sua desonra por ter nascido em sua linhagem, o nome de seus ancestrais seria ultrajado e todos os seus familiares seriam mal vistos. Essas consequências seriam lastimáveis (TSUNETOMO, 2004, p. 97-98).

Além de sujar a honra de toda a família e dos descendentes, o samurai poderia desonrar o nome do clã e de todo o feudo ao qual pertencia. Por isso, era comum e enraizado culturalmente que o guerreiro deveria realizar o Seppuku para que outras pessoas ao seu redor não sofressem com os erros cometidos em vida pelo guerreiro. Assim, é possível ponderar que o samurai se suicidava como dever e como uma obrigação no meio social.

Dessa maneira, mesmo que o ato fosse motivado para não causar transtorno à família, era movido também por uma questão presente na sociedade que traria problemas para as pessoas próximas ao samurai e até mesmo para o feudo. Por isso, no nosso ponto de vista, o suicídio estaria mais próximo do altruísmo, uma vez que 


\section{A morte pela espada: o suicídio ritualístico japonês analisado à luz da teoria de Émile Durkheim}

o indivíduo se sacrificaria em prol da família, sendo penetrado pelas correntes das crenças e dos valores presentes na sociedade japonesa. Nesse sentido, quando o samurai se suicida com o intuito de proteger o nome de sua família, ou em prol do senhor feudal, os atos são altruístas e se relacionam com a servidão e com a relação com o outro.

Apesar de tais pontos que nos permitem categorizar o suicídio samurai como altruísta, é importante salientar que nem todos os samurais necessariamente agiam de forma benevolente, altruísta e em concordância com as regras sociais presentes na sociedade nipônica. Como na maioria das sociedades, existiam pessoas que não seguiam os valores e, por vezes, estavam alienadas em relação às regras sociais. Assim, existiam aqueles samurais que se suicidavam por não ter mais motivos para viver, por não se encaixarem na sociedade e por questões individualistas. Esse estilo de samurai cometia tal ato como uma forma de fugir da realidade; sua ação, portanto, era individual para que unicamente ele não sofresse mais, e não voltada para preservar ou honrar os outros, sendo um ato egoísta.

Logo, quando analisamos o suicídio feudal japonês à luz da teoria de Durkheim, podemos observar que o Seppuku pode oscilar entre dois tipos de correntes do suicídio: o egoísta e o altruísta. Entretanto, como apresentamos anteriormente, os valores samurais são endossados por ideais que enaltecem o pertencimento à determinada sociedade e às regras sociais. O Seppuku era um ato final de servidão e de honra cujos benefícios não recaem somente sobre o samurai que cometia o suicídio. Era principalmente uma ação altruísta para que a honra não só dele, mas a de seus antepassados, a de seu feudo e a de seu senhor feudal não fossem afetadas. O suicídio é altruísta porque o samurai tem o dever de morrer pelos atos e falhas cometidas em vida, falhas que de alguma forma feriram a honra, o prestígio e causaram danos para outrem. Além disso, como uma prática que influenciava a sociedade feudal japonesa como um todo, o meio social ordenava que o indivíduo deixasse de existir.

Tal contexto possibilitou a ocorrência de diversos atos de Seppuku, muitos dos quais conhecidos ao longo da história. Alguns desses acontecimentos já foram abordados nesse estudo; além deles, é importante mencionar o caso dos 47 ronins, que ficou conhecido no longa-metragem ocidental de 2013 inspirado em uma lenda/ história japonesa conhecida como "47 Ronins". O filme conta uma famosa história japonesa sobre 47 samurais que se mataram coletivamente em prol do senhor feudal, seguindo ensinamentos e tradições do passado. A lenda dos 47 ronins é também conhecida como o "Incidente de Akô".

A versão mais conhecida da lenda é aquela em que 47 samurais foram obrigados a se tornarem ronins, ou seja, tiveram de abdicar da classe guerreira. A história se passa na província de Harima no Japão, e começa em 1701 durante o Shogunato Tokugawa, tempo em que o Seppuku não era mais uma prática social 
completamente endossada pelo shogunato, mas era ainda presente nos princípios dos guerreiros.

Em linhas gerais, a lenda reconta o incidente relacionado com o shogun Tsunayoshi que decidiu enviar dois senhores feudais para receber os mensageiros imperiais, Naganori Asano e Munehare Date. Como tais oficiais eram inexperientes, o shogun também designou um alto oficial, Yoshinaka Kira, para auxiliá-los. Após Yoshinaka Kira irritar-se com Asano por não lhe presentear com caros artigos em sinal de apreciação e respeito à sua ajuda durante o processo, reconta-se que, ao invés de ajudá-lo, Yoshinaka Kira prejudicava-o sempre que possível durante a missão. Asano, após suportar a situação por algum tempo, não tolerou mais os atos do oficial; assim, desembainhou sua espada e feriu o oficial. Diante do incidente e do ato abrupto de Asano, o shogun Tsunayoshi ordenou que Naganori Asano cometesse o Seppuku e não ordenou nenhuma punição ao oficial Kira. Apesar desse tipo de suicídio não ser apoiado mais pelo shogunato naquela época, a prática ainda era aceita quando um shogun ou o Imperador comandassem.

Nessa época, quando um governante era obrigado a cometer o Seppuku, suas posses eram confiscadas e sua família e servos eram deserdados e ordenados a se dispersar. Assim, como não podiam cometer o Seppuku, restava aos samurais somente se tornarem andarilhos. Após a morte de Asano e em devoção a ele, os samurais se vingaram do seu senhor feudal, sabendo que, ao final de sua ação, eles seriam comandados a cometer o Seppuku por parte do shogun Tsunayoshi. Os 47 ronins capturaram o oficial Yoshinaka Kira e o mataram em seguida. Após isso, enviaram ao shogun uma carta, na qual confessaram o crime e a responsabilidade pela morte do oficial e de alguns guardas. Em 1703, o shogun Tsunayoshi ordenou que 46 dos ronins cometessem Seppuku (BENESCH, 2014) e foram enterrados no mesmo local que Asano, no templo Sengakuji.

Mesmo nesse contexto, o suicídio pode ser interpretado em sua forma altruísta, visto que seguiram o soberano e fizeram isso com o objetivo de honrar a todo o clã e aos descendentes da família de Asano. Tais samurais não eram propriamente movidos por interesses individuais e particulares, mas foram mobilizados a se comportar de tal forma em prol de seu mestre e em concordância com as tradições samurais que ainda, apesar de terem diminuído, continuavam a permear culturalmente a classe guerreira. Tal fato demonstra como, em um momento inicial, regras sociais previamente socializadas podem continuar a influenciar a sociedade a despeito do surgimento de novas regras e imposições.

\section{Conclusão}

"Cada sociedade tem, portanto, em cada momento de sua história, uma aptidão definida para o suicídio. [...] Cada sociedade está predisposta a fornecer um 


\section{A morte pela espada: o suicídio ritualistico japonês analisado à luz da teoria de Émile Durkheim}

determinado contingente de mortos voluntários" (DURKHEIM, 2008, p. 168-173). A importância do suicídio no século XXI e temas relacionados à história e aos casos recorrentes de suicídio no Japão são um campo fértil de estudo, que nos permite aplicar teorias que compreendam questões culturais sobre o suicídio, e não somente aspectos psicológicos.

Observamos que, como Durkheim aponta, os valores samurais pairam como palavra de ordem e estão presentes nos valores da sociedade da época, fazendo com que o Seppuku seja uma forma ritualística e uma ação louvável, repetitiva e inerente ao meio social nipônico, sendo também um fato social. Em linhas gerais, o suicídio não era simplesmente um direito de morrer, mas constituía um dever da classe guerreira. Na maioria dos casos, o suicídio do samurai, como apresentado ao longo do texto, poderia ser considerado como altruísta por estar relacionado a um grande ideal e à ideia de se matar por um princípio social e não por interesses egoístas. Nota-se que, apesar de os samurais agirem em prol daqueles que devem defender em razão da estrutura social, existiriam aqueles que agiriam com um viés egoísta, de modo que, em um ato de desilusão e de perda, se matariam para tentar restaurar a honra.

A lâmina que o samurai ergue para matar e servir é uma mera ajudante na concretização do suicídio. Por estar integrado de forma demasiada à sociedade, por meio de ensinamentos e das regras que pairam como palavra de ordem e que eram passadas de geração em geração, o suicídio não era apenas aceito, como também esperado em diversas situações. Ou seja, em diversos sentidos, o meio social e também a cultura japonesa influenciavam a sociedade como um todo, impulsionando o comportamento dos samurais. Nesse sentido, a relação com a morte na sociedade japonesa precisa ser pensada não só à luz de fatos sociais, mas também com o intuito de adentrar de forma mais específica em uma análise que envolva o social e o cultural, algo que precisa ser aprofundado em futuros estudos sobre a temática.

O presente artigo faz um esforço inicial nesse sentido, analisando à luz da teoria de Durkheim as causas e as consequências do suicídio ritualístico samurai, visto que tais fatos podem elucidar alguns pontos sobre o Japão na atualidade. O suicídio japonês cometido pelos samurais era um ato ritualístico e influenciado pelo meio social, sendo um dos símbolos de honra e de altruísmo da tradição guerreira. De fato, apesar de ser insuficiente ponderar que as práticas dos samurais ainda existem na atualidade, casos isolados de suicídio no Japão se assemelham em alguns aspectos com as práticas do Seppuku (RUSSELL; METRAUX; TOHEN, 2016) e se relacionam com as pressões do meio social. Ademais, isso mostra como a tradições de uma sociedade podem perdurar em suas mais diversas camadas, envolvendo, inclusive, as motivações para se cometer o suicídio. 


\section{DEATH BY THE SWORD: JAPANESE RITUALISTIC SUICIDE ANALYZED IN THE LIGHT OF ÉMILE DURKHEIM'S THEORY}

ABSTRACT: Seppuku was a form of traditional feudal suicide in Japan and throughout history it was used by the Japanese warrior class (samurais) as a way to honorably die and serve their master. Considering that Japanese suicide can be interpreted as an imposition of the social environment and the rules which permeated the Japanese society of the time, this article aims to analyze samurai suicide as a social fact and in order to do so, the theoretical framework of Émile Durkheim's theory of suicide is used. From Durkheim's conceptions of the four typologies of suicide (selfish, altruistic, fatalistic, or anomic), the central hypothesis of this paper is that Seppuku can be categorized as a form of altruistic suicide which is closely related to the social environment and the Japanese culture. Therefore, we move away from psychological interpretations of suicide and recover the understanding that the act of committing suicide, when analyzing feudal Japan, must be studied in the light of the society of that time.

KEYWORDS: Suicide. Japan. Samurai. Seppuku. Émile Durkheim.

\section{MUERTE POR LA ESPADA: EL SUICIDIO RITUALISTA JAPONÉS analizado a la LUZ de la teoría de EMILE DURKHeIM}

RESUMEN: El Seppuku fue una forma tradicional de suicidio feudal japonés y a lo largo de la historia ha sido utilizado por la clase guerrera japonesa (samurái) como una forma de morir honorablemente y servir a su maestro. Al considerar que el suicidio japonés puede ser interpretado como una imposición del entorno social y de las reglas que impregnaban la sociedad japonesa de la época, este articulo tiene como objetivo analizar el suicidio samurai como un hecho social y para lograrlo utiliza el marco teórico de la teoría del suicidio de Émile Durkheim. Basándose en las concepciones de Durkheim sobre las cuatro tipologías de suicidio (egoísta, altruista, fatalista o anómico), la hipótesis central de este artículo es que el Seppuku puede ser categorizado como una forma de suicidio altruista que está estrictamente relacionada con el entorno social y la cultura japonesa.

PALABRAS CLAVE: Suicidio. Japón. Samurái. Seppuku. Émile Durkheim. 


\section{REFERÊNCIAS}

47 RONINS. Direção de Carl Rinsch. EUA; Reino Unido; Japão; Hungria, 2013. Lançado no Brasil em 2014.

BBC. Por que o Japão tem uma taxa de suicídios tão alta? 2015. Disponível em: https://www. bbc.com/portuguese/noticias/2015/07/150705_japao_suicidio_rb. Acesso em: 10 jan. 2016.

BENEDICT, Ruth. The Chrysanthemum and the Sword; Patterns of Japanese Culture. Charles E. Tuttle Co, 2nd edition,1954.

BENESCH, Oleg. Inventing the Way of the Samurai. Nationalism, Internationalism, and Bushidō in Modern Japan. United Kingdom: Oxford University Press, 2014.

DURKHEIM, Émile. As regras do método sociológico. São Paulo: Martins Fontes, 2002.

DURKHEIM, Émile. O suicídio. São Paulo: Martin Claret, 2008.

GIDDENS, Anthony. As Ideias de Durkheim. São Paulo: Cultrix, 1981.

GOES, Paulo de. O problema do suicídio em Santo Agostinho a luz do De civ. Dei, I. 227 p. Tese (doutorado), Universidade Estadual de Campinas, Instituto de Filosofia e Ciências Humanas, Campinas, SP, 2004. Disponível em: http://www.repositorio.unicamp.br/handle/ REPOSIP/279841. Acesso em: 3 ago. 2018.

HETCH, Jennifer Michael. Stay. A History of Suicide and the philosophies against it. Yale: Yale University Press, 2013.

IGA, Mamoru. Suicide of Japanese Youth. Sucide and Life-Threatening Behavior, Vol. 11, p.17-30, 1981.

IGA, Mamoru. The Thorn in the Chrysanthemum: Suicide and Economic Success in Modern Japan. Berkeley University of California Press, 1986.

MAEDA, Aya. How suicide has been conceived in Japan and in the Western World: Harakiri, Martyrdom and Group Suicide. Facing Finality: Cognitive and Cultural Studies on Death and Dying. Institute for Intercultural Communication, 2011.

MUELLER, Anna S. Does the Media Matter to Suicide? Examining the Social Dynamics Surrounding Media Reporting on Suicide in a Suicide-prone Community. Social Science and Medicine, Vol. 180, p. 152-159, 2017.

NITOBE, Inazo. A Alma do Samurai. São Paulo: Tahyu, 2005.

PINGUET, Maurice. A Morte Voluntária no Japão. São Paulo: Rocco, 1987. 
RUSSELL, Roxanne; METRAUX, Daniel; TOHEN, Mauricio. Cultural influences on suicide in Japan. PCN Frontier Review. Japanese Society of Psychiatry and Neurology, p. 2-4, 2016.

STACK, Steven. Emile Durkheim and Altruistic Suicide, Archives of Suicide Research. Vol 8, p. 9-22, 2004.

STACK, Steven; ABRUTYN, Seth Abrutin. "Suicide by Fire: Ethnicity as a Predictor of Self Immolation in the U.S.”. In: LESTER, D.; STACK, S. Suicide as Performance. New York: Transaction, p. 193-210, 2015.

STEINER, Philippe. A Sociologia de Durkheim. Rio de Janeiro: Editora Vozes, 2016.

FUSE, Toyomasa. Suicide and Culture in Japan: A Study of Seppuku as an Institutionalized Form of Suicide. Social Psychiatry, Vol. 15, p. 57-63, 1980.

TSAI, Yung-Mei; CHANDLER, Charless. Suicide in Japan and in the West. International Journal of Comparative Sociology. Vol. 34, issue 3-4, p. 244-258, 1993.

TSUNETOMO, Yamamoto. Hagakure: O livro do samurai. São Paulo: Conrad, 2004.

UENO, Kayoko. O suicídio é o maior produto de exportação do Japão? Notas sobre a cultura de suicídio no Japão. Revista Espaço Acadêmico, Vol. 44, 2005.

YOUNG, Jerome. Morals, Suicide, and Psychiatry: A View from Japan. Bioethics, Vol. 16, p. 412-424, 2002.

Recebido em 25/11/2018.

Aprovado em 11/09/2019. 